\title{
Cutaneous Vasculitis and Asthenia in a Patient with HCV-Related Chronic Liver Disease without Detectable Serum Cryoglobulinemia
}

\author{
Ibraheem G. Hosiki, MD \\ Department of Medicine, Division of Gastroenterology, \\ Faculty of Medicine, King Abdulaziz University, Jeddah, Saudi Arabia
}

\section{Correspondence}

Dr. Ibraheem G. Hosiki

Department of Medicine, Division of

Gastroenterology, Faculty of Medicine

King Abdulaziz University

P.O. Box 80215, Jeddah 21589, Saudi Arabia

e.M: ibraheemgh@windowslive.com

Submission: 31 August 2014

Accepted: 26 November 2014

\section{Citation}

Hosiki IG. Cutaneous vasculitis and asthenia in a patient with HCV-related chronic liver disease without detectable serum cryoglobulinemia. JKAU Med Sci 2015; 22(1): 39-43.

\begin{abstract}
This paper reports a case of 47-year-old lady with Hepatitis C virusrelated chronic liver disease who presented with asthenia and purpuric skin eruption involving her lower limbs. Punched skin biopsy from one of those lesions was consistent with small vessels vasculitis. Although Hepatitis C virus-related vasculitis is usually associated with cryoglobulinemia, in the present case the serum Cryoglobulins were not detected on three different occasions. Moreover, testing for indirect biomarkers for mixed cryoglobulinemia (rheumatoid factor and low complement-4) were negative. The patient treated with PEG-interferon alfa-2a plus ribavirin for 24 weeks and showed partial virological response. However, after two months from the start of treatment the cutaneous lesion disappeared completely with marked improvement of asthenia and remained asymptomatic during a follow-up period of 12 months after the antiviral treatment stopped. This case highlights that patients with Hepatitis C virus may have cutaneous vasculitis without detectable serum Cryoglobulins. Combination therapy with PEG-interferon alfa-2a and ribavirin is an effective treatment approach for such patients.
\end{abstract}

\section{Keywords}

Hepatitis C virus, Asthenia, Purpuric skin eruption, Small vessels vasculitis, Mixed cryoglobulinemia, Cutaneous vasculitis.

\section{Introduction}

$A$ bout $3 \%$ of the world's populations are chronically infected with hepatitis C virus (HCV), and it's a leading cause of chronic liver disease, cirrhosis and hepatocellular carcinoma ${ }^{[1]}$.

In addition to the liver inflammation, chronic HCV may be associated with a series of extrahepatic manifestations ranging from neuropathies to different skin diseases. A variety of skin manifestations can be seen in association with HCV infection, cutaneous vasculitis is the commonest one, and it is usually related to mixed cryoglobulinemia $(M C)^{[2-4]}$.

However, in this report, a lady with HCV-related chronic liver disease presented with asthenia and cutaneous vasculitis in the absence of serum MC.

\section{Case Report}

A 47-year-old woman was referred to the hepatology clinic because of abnormal liver enzymes. She also 
gave a history of the marked asthenia and purpuric skin eruption involving her lower limbs of 5 week's duration. She denied a history of joints pain or swelling. About twenty years ago, she was diagnosed to have HCV infection in another hospital but she didn't have a followup for that. No treatment for HCV had been offered for her at that time. There was no risk factor for acquiring the virus. The patient is known to have diabetes mellitus type 2 for eight years on Glibenclamide, and she was not on any other type of medication including herbal medicine. She denied smoking and alcohol abuse.

Physical examination revealed palpable purpuric rash over the lower limbs, distributed symmetrically, more over the legs with different sizes ranging from 3-5 mm. No other skin lesions over the rest of the body. General examination was unremarkable. No stigmata of chronic liver disease. The chest, cardiovascular, abdominal, rheumatological and neurological examinations were unremarkable.

Laboratory findings revealed; Leukocytes count 6,000/mmc (4.5-11.5), Hemoglobin $15.2 \mathrm{~g} / \mathrm{dL}$ (12-15), Platelets 160,000/mmc (150-450), Alanine transaminase (ALT)131 U/L (12-78), Aspartate aminotransferase (AST)186 U/L (15-37), Alkaline phosphatase (ALP) 176 U/L (36-50), Gamma-glutamyltransferase (GGT)168 U/L (5-85), Total bilirubin $16 \mathrm{umol} / \mathrm{L}$ (0-17), Direct bilirubin $8 \mathrm{umol} / \mathrm{L}$, Albumin $35 \mathrm{~g} / \mathrm{L}$ (40-47). Kidney function test and coagulation profile were normal. Urine analysis was negative for proteinuria and casts. Hepatitis $C$ virus-RNA level was 3,525,827 IU/mL, genotype 1 a. Hepatitis B surface antigen, hepatitis B core antibodies (total), Human immunodeficiency virus antibodies 1 \& 2 and Antineutrophil cytoplasmic antibodies (ANCA) were negative. Rheumatoid factor (RF), complements (C-3 \& C-4), Immunoglobulins (IgG) and Double Stranded DNA Antibodies were within normal ranges. Serum Cryoglobulins on three different occasions was negative. Anti-nuclear antibodies (ANA) was weakly positive. The skin biopsy of one of the purpuric lesions was consistent with small vessels vasculitis. Abdominal Ultrasound showed course echo pattern of the liver, normal portal vein, and there was no splenomegaly. Esophagogastroduodenoscopy (EGD) showed no varices. FibroScan score was (32 KPa), indicating advanced liver fibrosis (metavir fibrosis score stage-4).

The patient was treated with PEG-interferon alfa2a (180 $\mu \mathrm{g} /$ week) plus ribavirin $1000 \mathrm{mg} /$ day (that was before the availability of the new antiviral therapy (direct acting antiviral agents) in the country). She did not achieve rapid virological response (RVR) (defined as undetectable HCV RNA at week 4 of treatment). At week 12 of treatment the HCV-RNA level dropped to $34,088 \mathrm{lU} / \mathrm{mL}$. This level drop indicates that the patient achieved early virological response (EVR) (defined as $\geq 2$ $\log _{10} \mathrm{IU} / \mathrm{mL}$ (100 times) reduction in HCV RNA at week 12 of treatment). At week 24, HCV RNA remained positive
$(1,294,550 \mathrm{IU} / \mathrm{mL})$, so the decision was made to stop the treatment because HCV RNA would not continue to decline with continued treatment. However, after two months from the start of treatment, the skin rash resolved completely with marked improvement of asthenia and remained asymptomatic during a follow-up period of 12 months after discontinuation of treatment.

\section{Discussion}

Several extrahepatic manifestations have been reported in association with HCV infection. Extensive liver fibrosis, long-standing infection, advanced age, and female sex are important risk factors for developing extrahepatic manifestations ${ }^{[2]}$. During the natural course of HCV infection about $40-74 \%$ of patients might develop at least one extrahepatic clinical manifestation, the most common of which is mixed cryoglobulinemia $(\mathrm{MC})^{[2-4]}$. Cryoglobulins can be detected in up to $50 \%$ of HCV-infected individuals, but only a minority of patients (less than 15\%) will have symptoms related to cryoglobulinemia ${ }^{[4,5]}$.

MC is a systemic vasculitis affecting small and medium-sized blood vessels of the skin, kidneys, and nerves. Cutaneous vasculitis, ranging from palpable purpura and petechiae to large necrotic ulcerations, is the most common manifestation seen in patients with HCV-associated $M C^{[4]}$. MC is characterized by the deposition of circulating immunocomplexes containing rheumatoid factor (RF), IgG, HCV RNA, and complements on endothelial surfaces ${ }^{[5-7]}$. Besides the detection of MC in the serum of the patient with HCV-related vasculitis, other laboratory finding such as RF and low C4 may provide indirect evidence for the presence of MC.

In this case report the patient presented with asthenia and cutaneous vasculitis in association with $\mathrm{HCV}$ infection without detectable serum MC. It's possible that the patient with HCV-related vasculitis may have positive cryoglobulinemia from time to time ${ }^{[9]}$. However, the serum Cryoglobulin was not detected on three different occasions. Furthermore, testing for indirect biomarkers for MC, such as RF or low C4, were negative. On the other hand, the other possible causes of vasculitis like ANCA, HBV or HIV coinfection, or other autoimmune disorders were not present.

In the literature, there are only a few reports described patients with HCV-related vasculitis in the absence of detectable serum $\mathrm{MC}^{[8-10]}$. Terrier et al. ${ }^{[10]}$ found that patients with HCV-related vasculitis without MC have quite similar epidemiological, clinical, biological, virologic, and histological features of MC vasculitis, except for low rate of arthralgias and purpura and the absence of indirect biomarkers of MC.

HCV-related vasculitis without detectable MC probably results from immune complex mediated 
mechanism ${ }^{[5,9,10]}$. However, the exact pathogenic mechanism is not fully known.

Eradication of HCV with Interferon-based therapy is an effective treatment approach for cutaneous manifestations related to HCV MC ${ }^{[11-13]}$. The duration of therapy for patients with HCV MC vasculitis is similar to that in patients with HCV infection who do not have $\mathrm{MC}^{[11-}$ 13]. Cutaneous vasculitis related to HCV MC has a higher response rate to interferon-based therapy than neural or renal manifestations related to HCV MC vasculitis ${ }^{[12,13]}$. Although the clinical response is correlated with the improvement in HCV viremia, a small number of patients with HCV-MC vasculitis may remain in clinical remission despite the persistence of viremia ${ }^{[11-13]}$.

Saadoun et al. ${ }^{[12]}$ treated 72 patients with HCV MC vasculitis with Interferon alfa-2b (IFN alfa-2b) plus ribavirin ( $\mathrm{n}=32$ patients) or PEG-IFN alfa-2b plus ribavirin ( $n=40$ patients). These treatments were continued for at least 6 months ( mean duration 18 months with IFN alfa-2b and 13 months with PEG-IFN alfa-2b), and the patients were followed for a mean of 40 months after discontinuation of treatment. 6 months after completion of antiviral therapy, patients who received PEG-IFN alf$2 \mathrm{~b}$ plus ribavirin had somewhat higher rate of clinical response (68 versus 56\%), sustained virologic response (62 versus 53\%). According to the manifestations of vasculitis, complete improvement of purpura occurred in $86.3 \%$ of patients, neuropathy in $68.2 \%$, and renal involvement in $40.9 \%$. About $27 \%$ of the complete clinical responders were not sustained virologic responders. In a study published recently ${ }^{[14]}$, the same authors treated 23 patients with HCV MC vasculitis with triple therapy (PEGIFN alfa/ribavirin/protease inhibitor). Complete clinical response occurred in 13 patients (56.5\%) at week 24, and $69.6 \%$ had virological response (i.e., undetectable HCV-RNA) at week 24. Although such triple therapy was highly effective in this study, adverse effects were reported in $44 \%$ of cases and the majority of patients required erythropoietin and red cell transfusions. Such therapeutic regimen should be administered cautiously considering the high rate of side effects. Long-term follow-up is warranted to assess the sustained clinical and virological responses.

Approximately $15 \%$ of patients with HCV genotype 1 achieve rapid virologic response (RVR), patients who achieve RVR have the highest rate (up to $88 \%$ ) of sustained virologic response (SVR) (defined as HCV RNA is not detected 6 months after treatment end $)^{[15]}$. Unfortunately, the patient in this case report did not achieve RVR, so the prediction of achieving SVR was low. At week 24 of therapy the patient achieved partial virological response (defined as a decline in serum HCV RNA $\geq 2 \log _{10} \mathrm{IU} / \mathrm{mL}$ (100 times) from baseline at week 12 but does not develop undetectable HCV RNA at 24 weeks of treatment). This pattern of non-response occurs in approximately $15-20 \%$ of patients with HCV genotype ${ }^{[15]}$. Serum HCV RNA level in patients with partial virological response does not continue to decline with further therapy, and the treatment should be discontinued after 24 weeks if the virus remains detectable ${ }^{[15]}$. HCV genotype 1, high score fibrosis and high baseline viral load $>8 \times 10^{5} \mathrm{IU} / \mathrm{mL}$ were important factors associated with nonvirological response in the present case. However, after two months from the start of treatment the skin lesions disappeared completely with marked improvement of asthenia, and the patient remained asymptomatic during a follow-up period of 12 months following discontinuation of antiviral treatment. Besides its antiviral activity, IFN alfa also has antiproliferative and immunomodulatory properties ${ }^{[12]}$, which may explain the clinical response despite the persistence of viremia in this patient. However, retreatment of this patient with the new effective antiviral agents would result in clearance of the virus.

In summary, this case highlights that patients with HCV may have cutaneous vasculitis without detectable serum Cryoglobulins. Combination therapy with PEGinterferon afa-2a and ribavirin is an effective treatment approach in such patients.

\section{References}

[1] Shepard CW, Finelli L, Alter MJ. Global epidemiology of hepatitis C virus infection. Lancet Infect Dis 2005; 5(9): 558567.

[2] Cacoub P, Poynard T, Ghillani P, Charlotte F, Olivi M, Piette JC, Opolon P. Extrahepatic manifestations of chronic hepatitis C. Arthritis Rheum 1999; 42(10): 2204-2212.

[3] Medina J, Buey LG, Otero RM. Hepatitis C virus-related extrahepatic disease-aetiopathogenesis and management. Aliment Pharmacol Ther 2004; 20(2): 129-141.

[4] Galossi A, Guarisco R, Bellis L, Puoti C. Extrahepatic manifestations of chronic HCV infection. J Gastrointestin Liver Dis 2007; 16(1): 65-73.

[5] Cacoub P, Maisonobe T, Thibault V, Gatel A, Servan J, Musset $L$, Piette JC. Systemic vasculitis in patients with hepatitis C. J Rheumatol 2001; 28(1): 109-118.

[6] Charles ED, Dustin LB. Hepatitis C virus-induced cryoglobulinemia. Kidney Int 2009; 76(8): 818-824.

[7] Cacoub P, Saadoun D. Hepatitis C virus infection induced vasculitis. Clinic Rev Allerg Immunol 2008; 35(1-2): 30-39.

[8] Manna R, Todaro L, Latteri M, Gambassi G, Massi G, Grillo MR, Romito A, Caputo S, Gasbarrini GB. Leukocytoclastic vasculitis associated with hepatitis $C$ virus antibodies. Br J Rheumatol 1997; 36(1): 124-125.

[9] Lidove O, Cacoub P, Maisonobe T, Servan J, Thibault V, Piette $J C$, Leger JM. Hepatitis C virus infection with peripheral neuropathy is not always associated with cryoglobulinemia. Ann Rheum Dis 2001; 60(3): 290-292.

[10] Terrier B, Sène D, Dechartres A, Saadoun D, Ortonne N, Rouvier P, Musset L, Rigon MR, Maisonobe T,Cacoub P. Systemic vasculitis in patients with hepatitis $C$ virus infection with and without detectable mixed cryoglobulinemia. J Rheumatol 2011;38(1): 104-110. 
[11] Cacoub P, Saadoun D, Laminal N, Sene D, Lidove O, Piette JC. PEGylated interferon alpha-2b and ribavirin treatment in patients with hepatitis $C$ virus-related systemic vasculitis. Arthritis Rheum 2005; 52(3): 911-115.

[12] Saadoun D, Rigon MR, Thibult V, Piette JC, Cacoub P. Antiviral therapy for hepatitis $C$ virus-associated mixed cryoglobulinemia vasculitis. Arthritis Rheum 2006; 54(11): 3696-3706.

[13] Berk DR, Mallory SB, Keeffe EB, Ahmed A. Dermatologic disorders associated with chronic hepatitis C: effect of interferon therapy. Clinical Gastroenterol Hepatol 2007; 5(2): 142-151.

[14] Saadoun D, Rigon M R, Thibault V, Longuet M, Pol S, Blanc F, Pialoux G, Karras D B, Cazorla C, Vittecoq D, Musset L, Decaux O, Ziza J M, Lambotte O, Cacoub P. Peg-IFNa/ ribavirin/protease inhibitor combination in hepatitis $C$ virusassociated mixed cryoglobulinemia vasculitis: result at week 24. Ann Rheum Dis 2014; 73(5): 831-837.

[15] Shiffman M L. Factors Contributing to Failure When Treating Patients with Chronic Hepatitis C Virus Infection. Gastroenterol Hepatol 2007; 3 Suppl 20: 2-32. 


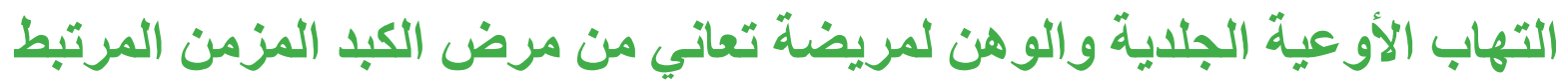

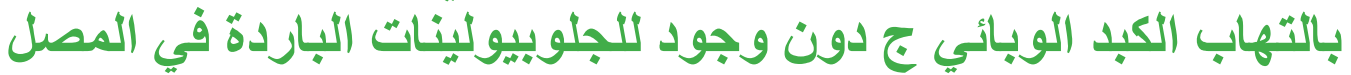

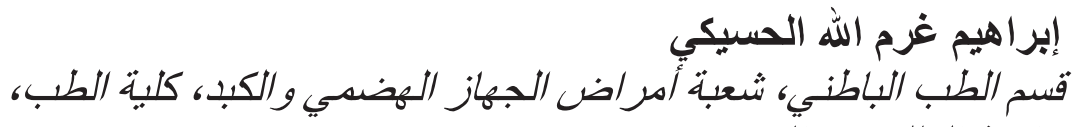 \\ جامعة الملك عبد العزبيز \\ جلة ـ المدلكة العربية السعودية العية
}

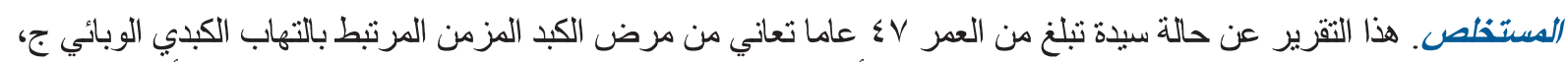

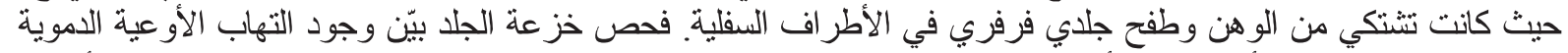

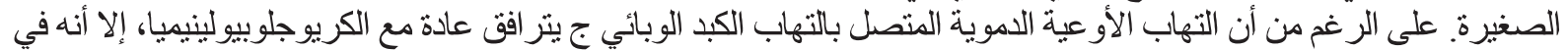

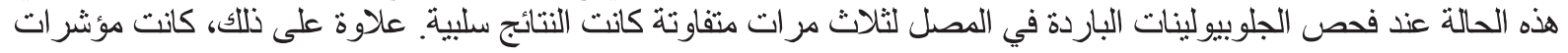

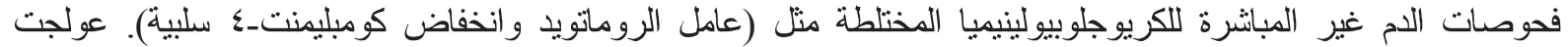

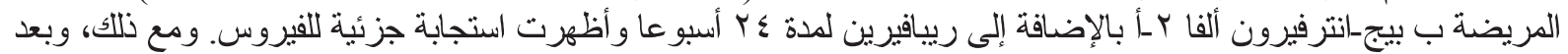

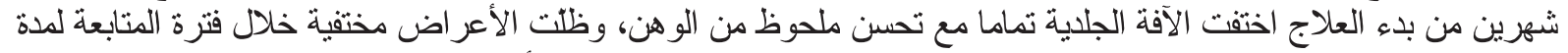

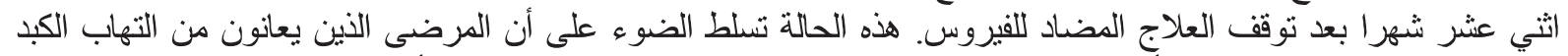

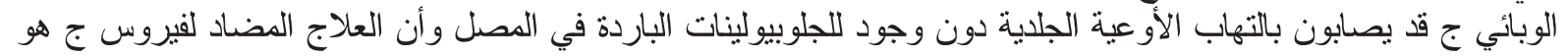

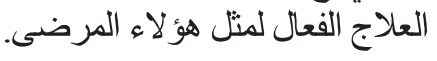

